\title{
Fractal Dimension of Fracture Surface in Rock Material after High Temperature
}

\author{
Z. Z. Zhang \\ State Key Laboratory for Geomechanics and Deep Underground Engineering, School of Mechanics and Civil Engineering, \\ China University of Mining \& Technology, Xuzhou, Jiangsu 221116, China
}

Correspondence should be addressed to Z. Z. Zhang; zzzcumt@163.com

Received 26 December 2014; Revised 21 May 2015; Accepted 25 May 2015

Academic Editor: Belal F. Yousif

Copyright (c) 2015 Z. Z. Zhang. This is an open access article distributed under the Creative Commons Attribution License, which permits unrestricted use, distribution, and reproduction in any medium, provided the original work is properly cited.

Experiments on granite specimens after different high temperature under uniaxial compression were conducted and the fracture surfaces were observed by scanning electron microscope (SEM). The fractal dimensions of the fracture surfaces with increasing temperature were calculated, respectively. The fractal dimension of fracture surface is between 1.44 and 1.63 . Its value approximately goes up exponentially with the increase of temperature. There is a quadratic polynomial relationship between the rockburst tendency and fractal dimension of fracture surface; namely, a fractal dimension threshold can be obtained. Below the threshold value, a positive correlativity shows between rockburst tendency and fractal dimension; when the fractal dimension is greater than the threshold value, it shows an inverse correlativity.

\section{Introduction}

Fracture surface records much material failure information left in the cracking process, so the fracture mechanism can be obtained with the analysis of fracture surface [1]. Fractal geometry is an effective method for analyzing the fracture surface quantificationally, and it can connect the micromechanism and macromechanism of rock failure when exploring the damage evolution law on microscale. In recent years, many scholars have used fractal geometry to study the morphology features of fracture surface. Shi et al. [2, 3] found that fractal dimension is related to the stress direction, not to the size of rock specimens. Zhao et al. [4, 5] estimated the fractal dimension of fault zone and obtained the changing law of fractal dimension with the variation of load, structure, lithology (marble, limestone, and sandstone), and particle size, which showed that the fractal dimension increases with the rising load before the macrofault formed and then remains constant; in addition it varies with the lithology. Cheng et al. [6] calculated the fractal dimension of crack system on profile of granite under triaxial compression and discussed the relation among fractal dimension, macromechanics characteristics, and test condition such as confining pressure and strain rate. Yi and Zhao [7] studied the fractal structure of cracked rock under uniaxial compression, and the results show the fractal dimension increases when the stress increases, and fractal dimension can be taken as a parameter to describe the process of rock fracture and there is good correlation among fractal dimension, uniaxial compressive strength, and rock weathering degree. Ju et al. [8] studied the propagation characteristic and energy dissipation of stress wave through fractal joint. Chen et al. [9] obtained the change law of fractal dimension of fracture surface on different loading directions with increasing water content.

We know that temperature plays an important role in high-temperature rock engineering such as geothermal energy development, high-temperature nuclear waste disposal, and postdisaster reconstruction of underground engineering. So it is necessary to study the high-temperature properties of rock. On the other hand, both the rockburst tendency index and fractal dimension of fracture surface can reflect the property of rock failure in some way, so a correlation may exist between rockburst tendency and fractal dimension, but so far no research is carried out in this area. In the present study, firstly the fracture surfaces were observed by SEM to get respective fractal dimension after different high temperature. And then the variation laws of rockburst tendency were obtained; lastly the relationship 
between them was studied further. This study is useful for rockburst prediction in high-temperature rock engineering and also can offer a new perspective in other related research.

\section{Experimental Procedure}

2.1. Preparation of Granite Specimens. Granite in this experiment is collected from Yanzhou mining area, Shandong Province, and it is mainly composed of feldspar, illite, pyroxene, and small amounts of other minerals. Limited to cubage of the heater and according to ISRM rock testing advice, rock specimens were processed into cylinder with diameter $25 \mathrm{~mm}$ and height $50 \mathrm{~mm}$. After carefully grinding on both upper and lower surfaces of rock samples using slice machine and sand paper, we make the specimens' parallelism of the upper-lower surface fluctuate within $0.05 \mathrm{~mm}$ and the flatness of the surface within $0.02 \mathrm{~mm}$. The longitudinal wave velocity through the rock specimens values $4500 \mathrm{~m} / \mathrm{s}$ under $25^{\circ} \mathrm{C}$, so the integrity and uniformity perform relatively well. Moreover, the average density of this kind of granite values $2.76 \mathrm{~g} / \mathrm{cm}^{3}$ in $25^{\circ} \mathrm{C}$, while the average uniaxial compressive strength values $191.9 \mathrm{MPa}$.

2.2. Testing Equipment and Methods. We mainly conduct the tests of uniaxial compression on rock specimens which have been natural cooling to normal temperature-dry after heated at high temperature $\left(25^{\circ} \mathrm{C}-1200^{\circ} \mathrm{C}\right)$. There are 6 groups as follows: $25^{\circ} \mathrm{C}, 200^{\circ} \mathrm{C}, 500^{\circ} \mathrm{C}, 800^{\circ} \mathrm{C}, 1000^{\circ} \mathrm{C}$, and $1200^{\circ} \mathrm{C}$, with 3 specimens in each group.

In this experiment, we use the electric hydraulic servovalve control system of pseudodynamic test of MTS815.02 in state key laboratory for geomechanics and deep underground engineering of CUMT to apply load (see Figure 1). Firstly, we heat the specimens, respectively, to a predetermined temperature with the heating rate of $2^{\circ} \mathrm{C}$ per minute using the high-temperature furnace MTS652.02; then, according to the actual experience of foreign scholars, to make sure the specimens heated evenly, we heat them in the predetermined temperature for 20 minutes; finally, the rock specimens are refrigerated naturally to $25^{\circ} \mathrm{C}$. The displacement control mode is applied in the process of rock loading, with the loading rate of $0.0015 \mathrm{~mm} / \mathrm{s}$; meanwhile, the control program Teststar II was also used to finish this experiment and record the values of related parameters. After the specimens were destroyed, the scanning electron microscopy S250MKIII was used to analyze the granite specimens' fracture surface with magnification of 20 thousand times.

\section{Results and Discussion}

3.1. The Variation of Fractal Dimension of Fracture Surface. The fracture surface of rock is rough in morphology totally. It seems chaotic macroscopicly with naked eyes, but $\mathrm{A}$ lot of research shows the rough fracture surface appears geometrical self-similarity and self-affinity with continuous magnification.

The SEM images of granite specimens' fracture surface under different temperature are shown in Figure 2. Other studies have shown that there is no relationship between the fractal dimension of fracture surface and specimen size [2]. The fractal dimension values are roughly similar from the small specimens such as $10 \mathrm{~mm}$ to the larger $400 \mathrm{~mm}$ specimens, even the fault of thousands of kilometers, which prove that the rock fracture surface definitely has self-similar structure, and it is fractal in geometry. Therefore, to get the change law of fractal dimension of rock fracture surface at different temperature, we make fractal analysis of the SEM images of the granite specimens' fracture surface.

There are various definitions for fractal dimension, such as Hausdroff dimension, information dimension, similar dimension, correlation dimension, and capacity dimension [10]. The box-counting dimension is used in this paper, as it has a series of equivalent definitions, and, for approximate calculation, it usually expressed by

$$
d_{f}=\lim _{k \rightarrow \infty} \frac{\ln N_{\delta_{k}}(F)}{-\ln \delta_{k}},
$$

where $\delta_{k}$ indicates the side length of the grid; $N_{\delta_{k}}$ states the number of the grids at the intersection of fractal set $F$.

Table 1 shows that the fractal dimension values of fracture surface in granite specimen are between 1.44 and 1.63, and it grows at an exponential rate with the increase of temperature approximately (see in Figure 3). When the heating temperature is over $600^{\circ} \mathrm{C}$, the fractal dimension is about $1.60,11.1 \%$ higher than the value at room temperature.

According to Figure 2, intergranular fracture and cleavage fracture are the main thermal cracking form in the condition of the temperature below $200^{\circ} \mathrm{C}$; above this temperature, transgranular cracks increase significantly; in addition, microvoids and large intergranular crack may become new damage source between $200^{\circ} \mathrm{C}$ and $800^{\circ} \mathrm{C}$; both transgranular crack and shear sliding band exist on fracture surface over $800^{\circ} \mathrm{C}$; there are many plastic dimples, microhollows on the fracture surface, with thermal melting behavior appearing over $1200^{\circ} \mathrm{C}$. Based on the fractal theory, the energy will dissipate more when the fractal dimension becomes larger, and the energy consumed by intergranular fracture and cleavage fracture is less than that consumed by transgranular fracture, so the fractal dimension of fracture surface formed by intergranular fracture is smaller than that formed by transgranular fracture. To sum up, the fractal dimension of fracture surface increases with the increase of temperature.

\subsection{The Relationship between Rockburst Tendency and Fractal} Dimension of Fracture Surface. Rockburst tendency is the property that the elastic strain energy accumulated in rock mass releases suddenly when the stress exceeds its strength. It is the inherent attribute of rock and is internal cause and necessary condition in rock burst [11]. There are several rockburst tendency indexes proposed to evaluate the rockburst risk, and Tang et al. [12-14] suggested some new ones such as residual energy index and the effective burst energy index for supplying a gap of familiar indexes.

We select the effective burst energy index as the rockburst tendency index, which is the ratio of the prepeak stored elastic energy and the postpeak dissipative energy [13], and it is 

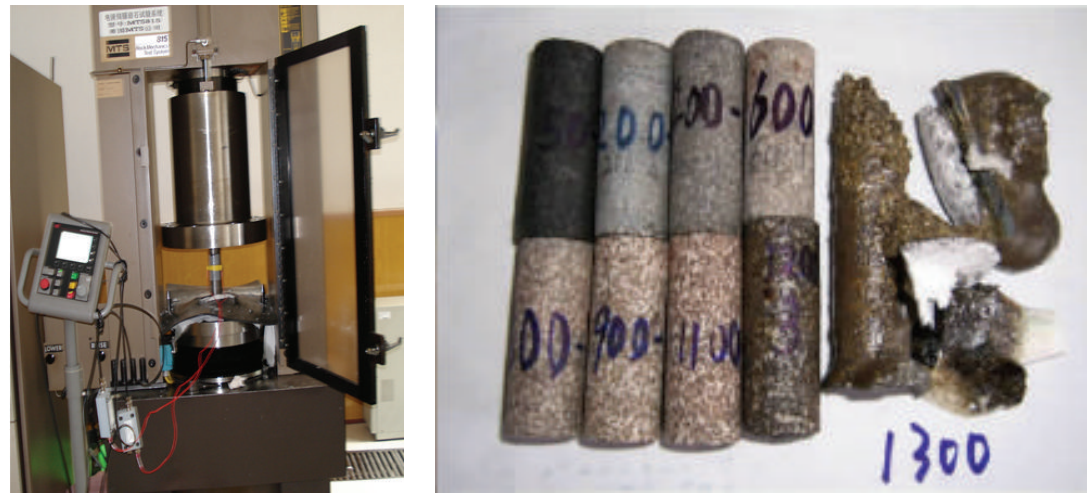

FIGURE 1: Appearance of MTS815.02 system and heated rock samples.

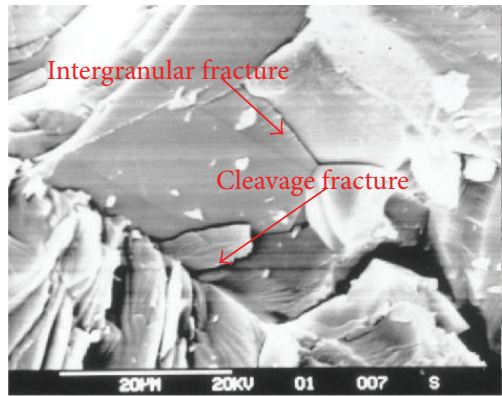

(a)

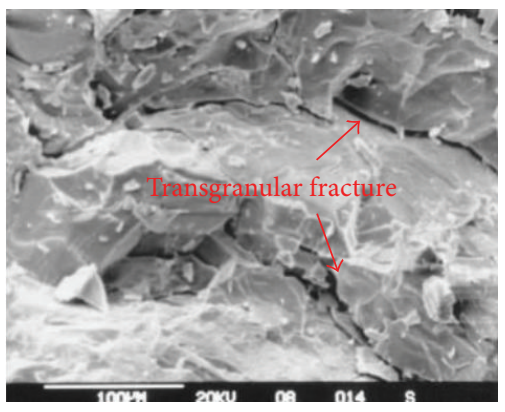

(d)

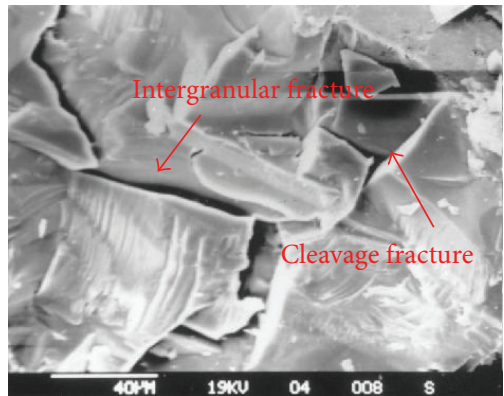

(b)

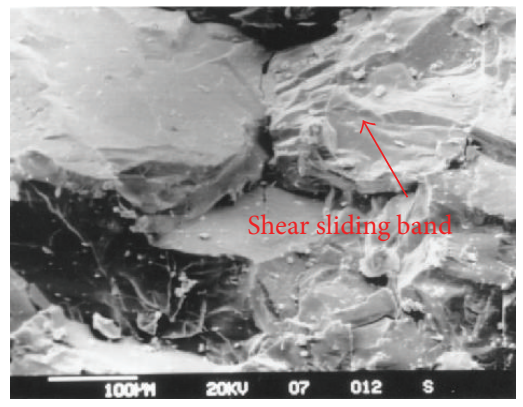

(e)

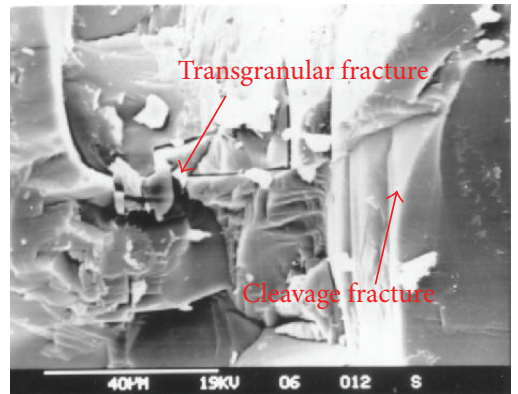

(c)

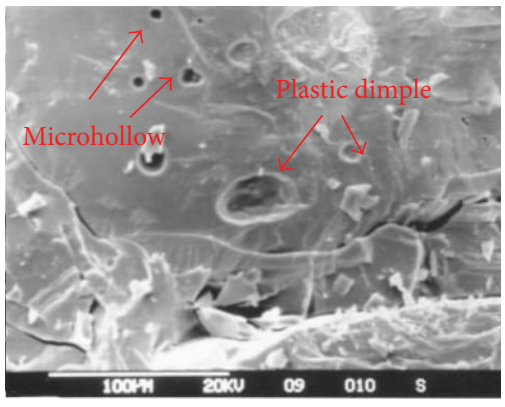

(f)

FIGURE 2: SEM images of fracture surfaces in rock samples under different temperature: (a) $25^{\circ} \mathrm{C}$, (b) $200^{\circ} \mathrm{C}$, (c) $500^{\circ} \mathrm{C},(\mathrm{d}) 800^{\circ} \mathrm{C}$, (e) $1000^{\circ} \mathrm{C}$, and (f) $1200^{\circ} \mathrm{C}$.

the ratio of the prepeak stored elastic energy and the postpeak dissipative energy. It can be expressed by the ratio between the area below the peak unloading line $\mathrm{CD}$ and the area below the postpeak curve in Figure 4. It should be emphasized that, in the calculation of the prepeak elastic energy, the slope of the rock unloading curve will generally be the same with the line segment of loading curve by experience [10], which can be used to calculate the stored elastic energy of rock under peak load.

The values of rockburst tendency indexes at different temperature are shown in Table 2. Data in Tables 1 and 2 are plotted in Figure 5. It can be seen that the rockburst tendency of granite specimens and the fractal dimension of fracture surfaces enlarge with the heating temperature in the condition of the temperature below $200^{\circ} \mathrm{C}$; however, when the temperature is higher than $200^{\circ} \mathrm{C}$, with the increase of temperature, the fractal dimension enlarges, while the rockburst tendency index decreases.

Figure 6 shows the change law of rockburst tendency index with the fractal dimension. It can be obtained that they follow a quadratic polynomial function.

The general form of the quadratic polynomial function can be expressed by

$$
K_{\mathrm{eff}}=A\left(d_{f}-\widehat{d}_{f}\right)^{2}+B,
$$

where $K_{\text {eff }}$ is the effective burst energy index, $A$ and $B$ both are rock material constant, and they may be related with the rock microstructure and the load form, $\widehat{d}_{f}$ denotes the fractal dimension threshold, and there is a positive 
TABLE 1: Fractal dimensions of fracture surface after different temperature.

\begin{tabular}{|c|c|c|c|c|c|c|c|c|c|}
\hline Temperature $/{ }^{\circ} \mathrm{C}$ & & 25 & & & 200 & & & 500 & \\
\hline Fractal dimension & 1.39 & 1.40 & 1.53 & 1.55 & 1.49 & 1.55 & 1.56 & 1.66 & 1.58 \\
\hline Average value & & 1.44 & & & 1.53 & & & 1.60 & \\
\hline Temperature $/{ }^{\circ} \mathrm{C}$ & & 800 & & & 1000 & & & 1200 & \\
\hline Fractal dimension & 1.54 & 1.67 & 1.56 & 1.58 & 1.62 & 1.69 & 1.63 & 1.61 & 1.62 \\
\hline Average value & & 1.59 & & & 1.63 & & & 1.62 & \\
\hline
\end{tabular}

TABLE 2: Rockburst tendency indexes of rock samples after different temperature.

\begin{tabular}{lcccccccc}
\hline Temperature $/{ }^{\circ} \mathrm{C}$ & & 25 & & 200 & & 500 \\
\hline Effective burst energy index & 3.10 & 3.54 & 2.96 & 3.55 & 4.68 & 3.89 & 1.92 & 1.78 \\
Average value & & 3.20 & & & 4.04 & & 1.70 \\
\hline Temperature $/{ }^{\circ} \mathrm{C}$ & & 800 & & & 1000 & 0.80 & 1200 \\
\hline Effective burst energy index & 2.21 & 1.99 & 2.79 & 0.32 & 0.56 & 0.65 & 0.44 & 0.68 \\
Average value & & 2.33 & & & 0.51 & & 0.74 \\
\hline
\end{tabular}

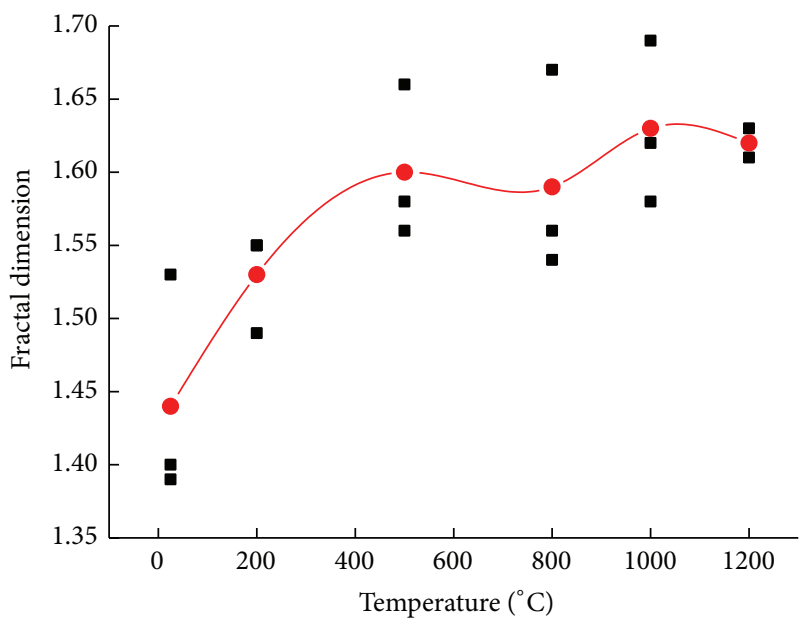

- Scattered points

- - Average points

- Changing curve

Figure 3: Changes in fractal dimension of fracture surface with temperature.

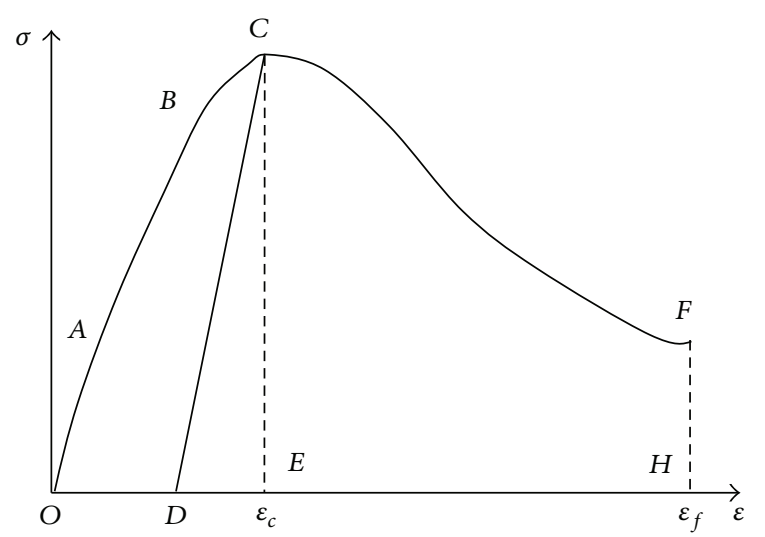

FIgURE 4: Typical stress-strain curve under uniaxial compression for rock.

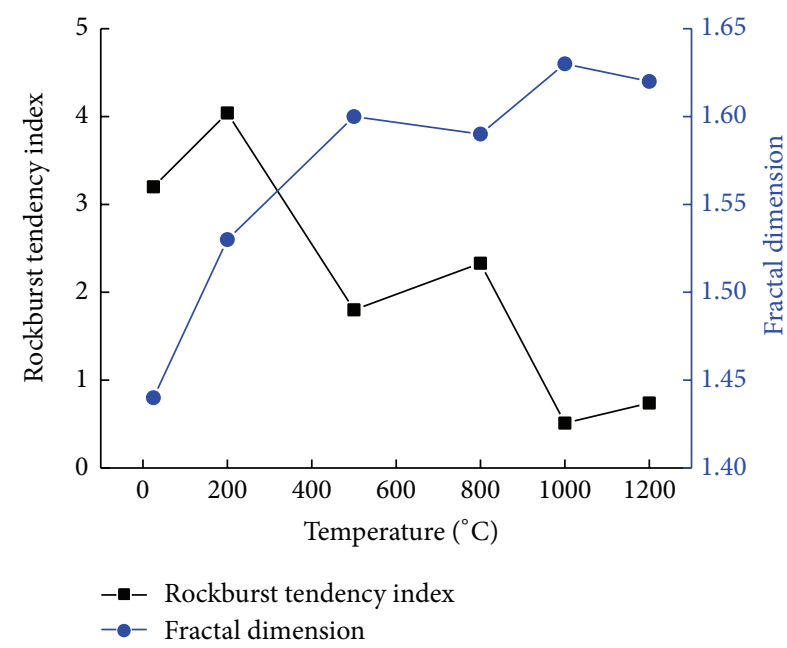

FIGURE 5: Relationship between the rockburst tendency index and the fractal dimensions of fracture surface after different temperature.

correlativity between the rockburst tendency index and the fractal dimension when $d_{f} \leq \widehat{d}_{f}$, an inverse correlativity when $d_{f}>\widehat{d}_{f}$.

By Figure 6, for the granite specimens in the tests, the fractal dimension threshold $\widehat{d}_{f}$ is 1.50 . That is to say, when the fractal dimension $d_{f} \leq 1.50$, the larger the value of $d_{f}$ is, the stronger the rockburst tendency is; whereas when the fractal dimension $d_{f}>1.50$, the rockburst tendency is weakened with the value of $d_{f}$.

This law can be proved by the relationship between the actual propagation velocity and the apparent propagation velocity of fractal crack [1]:

$$
\frac{V}{V_{0}}=\left(\frac{d}{\Delta a}\right)^{1-D} .
$$

Here, $V$ and $V_{0}$, respectively, represent the actual propagation velocity and the apparent velocity, $d$, the grain size, $\Delta a$, 


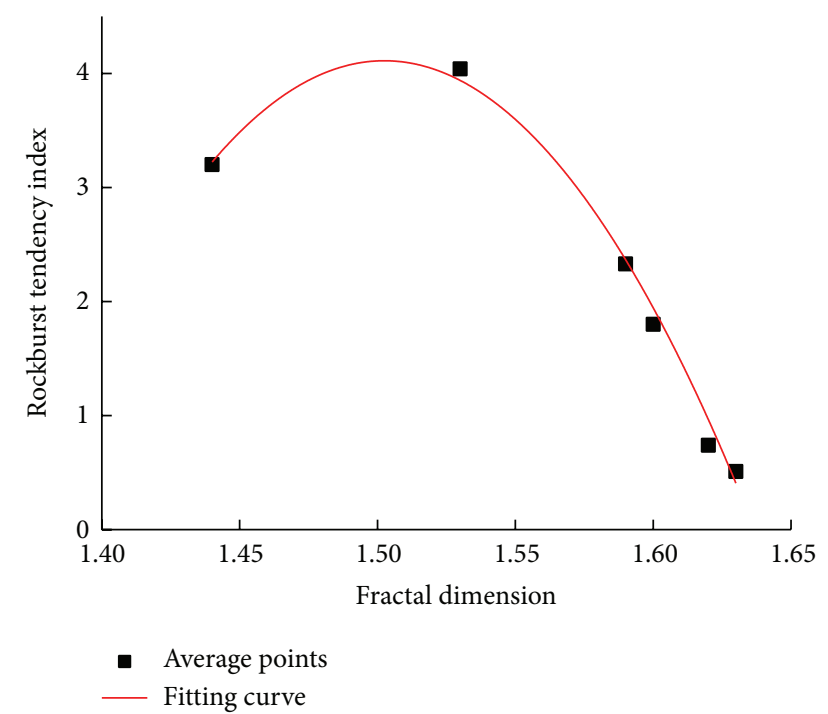

FIGURE 6: Changes in rockburst tendency index with fractal dimension of fracture surface.

the propagation step of crack, and $D$, the fractal dimension of crack.

From (3), it is seen that if the actual propagation velocity, reflecting the power of surface energy, is constant, the smaller fractal dimension signifies larger apparent propagation velocity, and the rock breaks more severe; thus the burst tendency is stronger.

Figure 6 shows that the above analysis only corresponds to the interval of $d_{f}>\widehat{d}_{f}$. For the interval of $d_{f} \leq \widehat{d}_{f}$, we consider that the larger the fractal dimension is, the more difficult the rock specimen breaks, so the critical stress is greater with more elastic strain energy accumulated, and the rock specimen breaks more tempestuously; namely, the burst tendency is stronger.

Rockburst resulted from formation and expansion of a large number of cracks. The cracks make the rock split into pieces, while getting the elastic strain energy to be converted into kinetic energy, which leads to the dynamic failure of rock [15]. Therefore, the fractal dimension of rock fracture surface is related with the micromechanical behavior and energy dissipation and energy release during the rock failure process, and it can reflect the intensity of rock failure, that is, the degree of rockburst tendency.

\section{Conclusions}

(1) The fractal dimension values of fracture surface in granite are between 1.44 and 1.63, and when the heating temperature increases, the fractal dimension of the fracture surface generally increases, roughly in change of an exponential form; while the temperature is over $600^{\circ} \mathrm{C}$, the fractal dimension is about $1.60,11.1 \%$ higher than the value at room temperature.

(2) There is a quadratic polynomial relationship between the rockburst tendency index and the fractal dimension of fracture surface. A fractal dimension threshold of $\widehat{d}_{f}$ is found, and there is a positive correlativity between the rockburst tendency index and the fractal dimension when $d_{f} \leq \widehat{d}_{f}$, an inverse correlativity when $d_{f}>\widehat{d}_{f}$. For the granite specimens in these experiments, the fractal dimension threshold $\widehat{d}_{f}=$ 1.50 .

\section{Conflict of Interests}

The author declares that there is no conflict of interests regarding the publication of this paper.

\section{Acknowledgments}

This work had been financially supported by the Fundamental Research Funds for the Central Universities (no. 2014QNA80) and the Natural Science Foundation of Jiangsu Province (no. BK20140189).

\section{References}

[1] H. Xie, Introduction to Fractal in Rock Mechanics, Science Press, Beijing, China, 1996.

[2] X. Shi and Z. Niu, "Fractal dimension of fractured surface of rocks," Chinese Science Bulletin, vol. 21, pp. 1845-1846, 1991.

[3] X. Shi, Z. Niu, and H. Xu, "The fractal dimension of the fractured surface of rocks," Acta Geophysica Sinica, vol. 35, no. 2, pp. 154-159, 1992.

[4] Y. Zhao, J. Huang, and J. Geng, "The fractal characteristics of fracture development in compressed rock specimens," Scientia Geologica Sinica, vol. 29, no. 2, pp. 137-143, 1994.

[5] Y. Zhao, "Cracks development and fractal dimension in rocks under pressure," Chinese Science Bulletin, vol. 40, no. 7, pp. 621623, 1995.

[6] H. Cheng, K. Wu, and C. Zhuang, "Fractal dimension of granite fracture system under solid medium tri-axial compression," Progress in Geophysics, vol. 10, no. 1, pp. 92-103, 1995.

[7] S. Yi and W. Zhao, "The fractal characteristics of rock fracture in dam foundation of the three gorges project under uniaxial compression," Chinese Journal of Rock Mechanics and Engineering, vol. 18, no. 5, pp. 520-523, 1999.

[8] Y. Ju, L. Sudak, and H. Xie, "Study on stress wave propagation in fractured rocks with fractal joint surfaces," International Journal of Solids and Structures, vol. 44, no. 13, pp. 4256-4271, 2007.

[9] X. Chen, Y. Li, X. Huang, and S. Du, "Study on geometrical properties of fracture appearance in gypsum breccia based on 3d GIS statisti," Chinese Journal of Rock Mechanics and Engineering, vol. 27, supplement 2, pp. 3541-3546, 2008.

[10] N. Sivakugan, S. K. Shukla, and B. M. Das, Rock Mechanics: An Introduction, Taylor \& Francis, Boca Raton, Fla, USA, 2013.

[11] Z. Zhang, F. Gao, M. Ji, and T. Zhang, "Prediction of rock burst potential by analysis of ultrasonic velocity data," Disaster Advances, vol. 3, no. 4, pp. 416-420, 2010.

[12] L. Tang, C. Pan, and W. Wang, "Surplus energy index for analyzing rock burst proneness," Journal of Central South University of Technology, vol. 33, no. 2, pp. 129-132, 2002.

[13] F. Gao, Z. Zhang, and X. Liu, "Research on rock burst proneness index based on energy evolution in rock," Disaster Advances, vol. 5, no. 4, pp. 1367-1371, 2012. 
[14] A. M. Linkov, "Rockbursts and the instability of rock masses," International Journal of Rock Mechanics and Mining Sciences and Geomechanics, vol. 33, no. 7, pp. 727-732, 1996.

[15] T. Li, Y. Wang, and M. Zhang, "Fractal properties of crack in rock and mechanism of rock-burst," Chinese Journal of Rock Mechanics and Engineering, vol. 19, no. 1, pp. 6-10, 2000. 

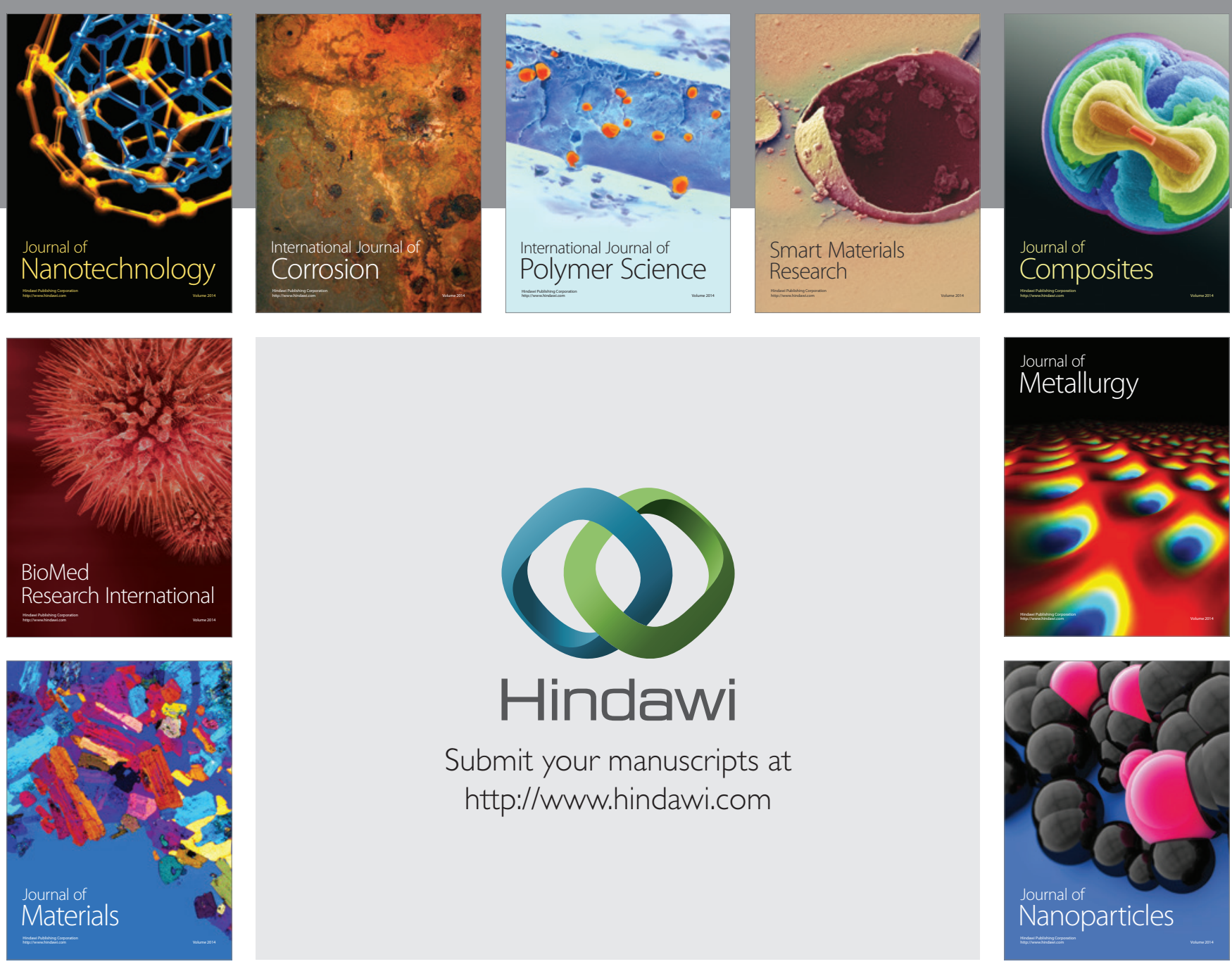

Submit your manuscripts at http://www.hindawi.com
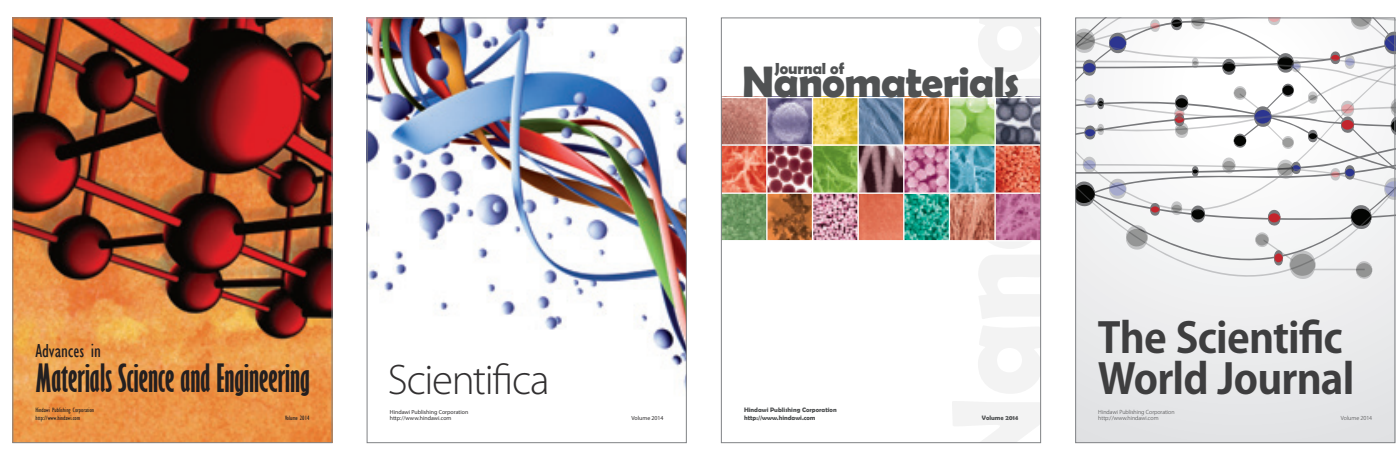

\section{The Scientific World Journal}
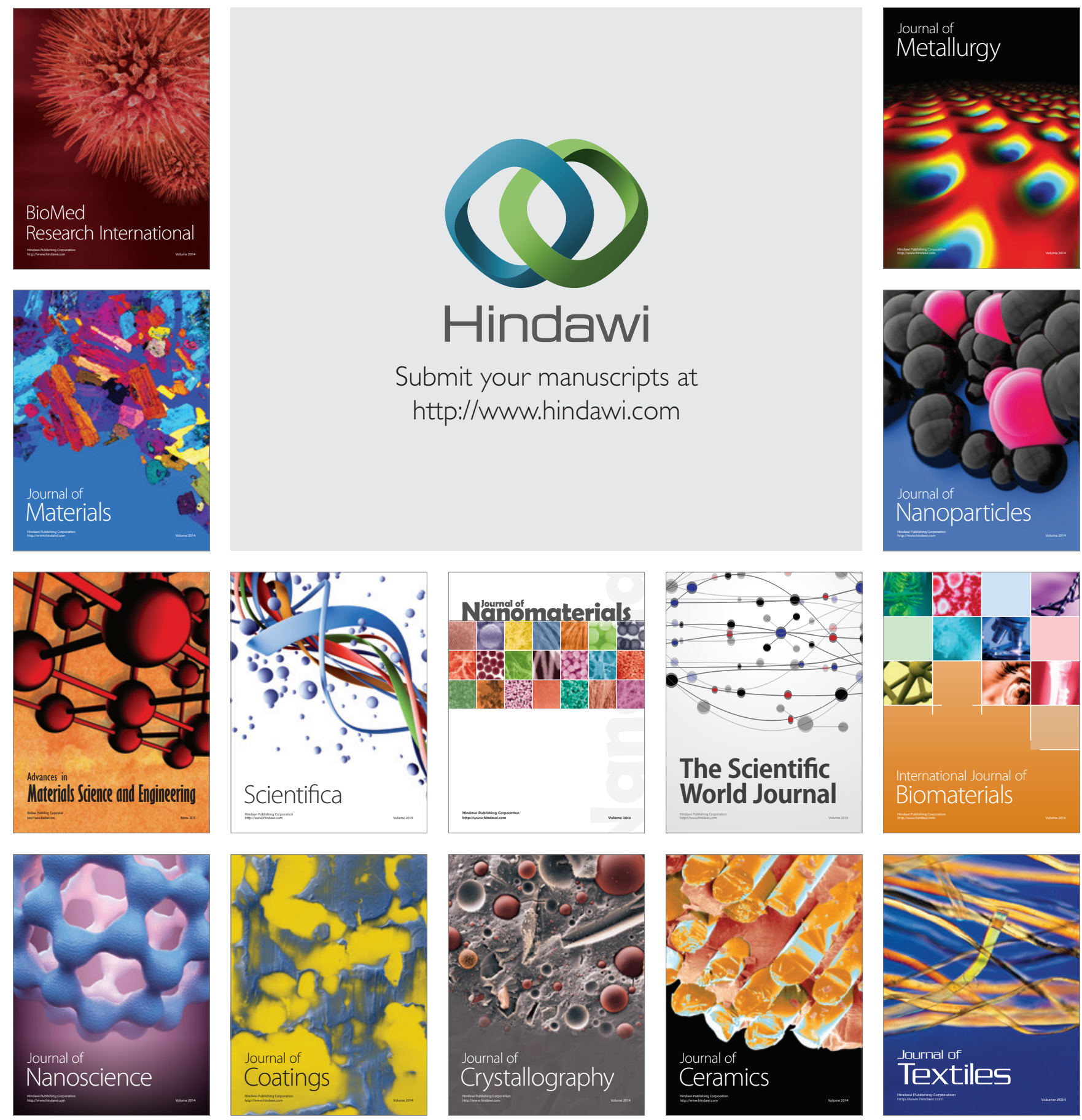